\title{
FAKTOR KUNCI KESUKSESAN STUDENTPRENEUR
}

\author{
Vanessa Gaffar ${ }^{1}$, Heny Hendrayati ${ }^{2}$ \\ ${ }^{1,2}$ Program Studi Manajemen, Fakultas Pendidikan Ekonomi dan Bisnis, \\ Universitas Pendidikan Indonesia, Bandung, Indonesia \\ vanessa@upi.edu¹, henyhendrayati@upi.edu²
}

\begin{abstract}
One way to reduce the level of unemployment in Indonesia is to provide an impetus for entrepreneurship. The problem exists when there is low interest in entrepreneurship among young people, especially students. Therefore it is necessary to raise their entrepreneurial spirit through entrepreneurship education as a lifelong learning process (longlife learning process). The purpose of this research is to find out and compare the key success factors of entrepreneurship in three tertiary institutions in Indonesia, namely UPI, UNPAD and ITB. The study was conducted on 300 student entrepreneurs from three universities with random sampling techniques. The main success factor is measured by 1) Technical procedures 2) Company structure 3) Human resources in the company 4) Company financial structure and 5) Marketing and Productivity. The results show that the highest point lies in technical procedures while the lowest is human resources in the company. Overall, there were no significant differences in the key factors for entrepreneurial success at the three universities. Human resource development must be increased in terms of turnover, behavior, and commitment.
\end{abstract}

Keywords: key success factors, studentpreneur, lifelong learning process

\begin{abstract}
Abstrak
Salah satu cara yang dilakukan untuk mengurangi tingkat pengannguran di Indonesia adalah dengan memberikan dorongan untuk berwirausaha. Masalahnya ada bila ada minat rendah terhadap kewirausahaan di kalangan anak muda, terutama mahasiswa. Oleh karena itu perlu untuk membangkitkan semangat wirausaha mereka melalui pendidikan kewirausahaan sebagai proses belajar sepanjang hayat (longlife learning process). Tujuan dari penelitian ini adalah untuk mengetahui dan membandingkan faktor kunci keberhasilan wirausaha di tiga perguruan tinggi di Indonesia yaitu UPI, UNPAD dan ITB. Penelitian dilakukan terhadap 300 pengusaha mahasiswa dari tiga universitas dengan teknik random sampling. Faktor keberhasilan utama diukur dengan 1) Prosedur teknis 2) Struktur perusahaan 3) Sumber daya manusia di perusahaan 4) Struktur keuangan perusahaan dan 5) Pemasaran dan Produktifitas. Hasilnya menunjukkan bahwa titik tertinggi terletak pada prosedur teknis sedangkan yang terendah adalah sumber daya manusia di perusahaan. Secara keseluruhan, tidak ada perbedaan signifikan pada faktor kunci keberhasilan wirausaha di tiga universitas. Pengembangan sumber daya manusia harus ditingkatkan dalam hal omset, perilaku, dan komitmen.
\end{abstract}

Kata kunci: key success factors, studentpreneur, lifelong learning process

Corresponding author: Email : vanessa@ upi.edu

History of article : Received: Juli 2019, Revised : September 2019, Published: November 2019 


\section{PENDAHULUAN}

Data BPS Februari 2016, data menunjukkan bahwa lulusan yang menganggur mencapai 695.000 orang. Ini meningkat 20 persen dibandingkan data pada bulan Februari 2015. Tercatat pada bulan Mei 2016 oleh BPS bahwa tingkat pengangguran di Indonesia mencapai 7,02 juta orang $(5,81$ persen dari total populasi), 6,22\% dari total (sekitar 436 ribu jiwa) adalah sarjana, atau setidaknya lulusan sarjana. Berdasarkan data di atas dapat kita lihat bahwa perguruan tinggi di Indonesia memainkan peran penting untuk menghasilkan siswa menjadi lulusan mandiri dan dapat memberikan pekerjaan setelah lulus. Universitas bertanggung jawab untuk mendidik dan memberi keterampilan berwirausaha kepada lulusannya dan memotivasi mereka untuk memilih kewirausahaan sebagai karir mereka. Universitas perlu menerapkan pola pembelajaran wirausaha yang konkrit berdasarkan masukan empiris untuk membekali siswa dengan pengetahuan yang berarti guna mendorong semangat kewirausahaan untuk berwirausaha ( $\mathrm{Wu}$ dan $\mathrm{Wu}, 2008$ ).

Saat ini, mahasiswa ditargetkan untuk pengembangan kewirausahaan di Indonesia. Ini karena mahasiswa adalah agen perubahan. Sebagai agen perubahan mereka tidak hanya bertindak sebagai pencari kerja namun selanjutnya mengaku sebagai pencipta lapangan kerja untuk bisa mengatasi masalah tingkat pengangguran. Semoga pertumbuhan semangat kewirausahaan akan banyak menghadirkan usaha kecil dan menengah baru, yang terbukti lebih tahan terhadap krisis daripada bisnis besar. Dari semua program dan kegiatan dalam meningkatkan kewirausahaan, tujuan utamanya adalah menjadikan Indonesia mandiri sehingga dapat meningkatkan daya saing bangsa. Untuk mewujudkan tujuan besar ini, diperlukan peningkatan semangat kewirausahaan mahasiswa melalui pendidikan kewirausahaan sebagai proses belajar seumur hidup. (Vanessa \& Heny, 2016).
Saat ini, mahasiswa ditargetkan untuk pengembangan kewirausahaan di Indonesia. Ini karena mahasiswa adalah agen perubahan. Sebagai agen perubahan mereka tidak hanya bertindak sebagai pencari kerja namun selanjutnya mengaku sebagai pencipta lapangan kerja untuk bisa mengatasi masalah tingkat pengangguran. Semoga pertumbuhan semangat kewirausahaan akan banyak menghadirkan usaha kecil dan menengah baru, yang terbukti lebih tahan terhadap krisis daripada bisnis besar. Dari semua program dan kegiatan dalam meningkatkan kewirausahaan, tujuan utamanya adalah menjadikan Indonesia mandiri sehingga dapat meningkatkan daya saing bangsa. Untuk mewujudkan tujuan besar ini, diperlukan peningkatan semangat kewirausahaan mahasiswa melalui pendidikan kewirausahaan sebagai proses belajar seumur hidup. (Vanessa \& Heny, 2016)

Tujuan dari penulisan ini adalah untuk mengetahui, mengidentifikasi dan membandingkan faktor kunci keberhasilan usaha kecil dan menengah yang dilakukan oleh mahasiswa yang nantinya dalam makalah ini selanjutnya disebut sebagai studentpreneur.

\section{KAJIAN PUSTAKA}

Sebagian besar literatur tentang siswa berfokus pada siswa dan menjadikan siswa sebagai (calon) peserta didik yang sadar dan mendapatkan berbagai tingkat perkembangan dan berbagai bentuk permodalan. Sebuah literatur yang luas tentang pilihan universitas, membingkai siswa sebagai pengambil keputusan dalam memilih universitites dan dipengaruhi oleh berbagai faktor sosiologis dan ekonomi dalam proses (Perna, 2006) di (Mars, Slaughter, \& Rhoades, 2008). Dari perspektif psikologis sosial, para ilmuwan telah menganalisis dampak pendidikan tinggi terhadap perkembangan kognitif, psikososial, dan moral siswa (Pascarella \& Terenzini, 2005); (Mars, Slaughter, \& Rhoades, 2008). Yang lain telah meneliti faktor sosial dan ekonomi yang membentuk persistensi siswa (misalnya, Nora, Cabrera, 
Hagedorn, \& Pascarella, 1996) (St. John, 2003), (Tinto, 1993). Dari perspektif ekonomi berdasarkan teori human capital, peran siswa di tingkat sarjana dan sarjana telah dikonseptualisasikan sebagai siswa yang memperoleh keterampilan dalam profesi mereka dan untuk mengembangkan ketrampilan dan perilaku mereka selama perjalanan pendidikan mereka sampai setelah lulus yang dapat digunakan di pasar tenaga kerja (Mars, Slaughter, \& Rhoades, 2008). Oleh karena itu, karya pembingkaian siswa sebagai agen aktif yang secara individu dan kolektif berusaha memanfaatkan perubahan di akademi. Para siswa dilemparkan dalam peran, bukan karena peserta dididik namun sebagai kritikus dan agen perubahan. Mereka bukan objek aktivitas universitas tapi subjek yang menantang dan membentuk kembali organisasi.

Pengusaha didefinisikan dalam banyak cara dalam literatur. Hal yang sama berlaku untuk Pengusaha Mahasiswa namun definisinya kurang spesifik. Menurut Baghai, Coley, \& White (2000); Purwal (2001), Marchand \& Hermens (2015) wirausahawan memandang diri mereka sebagai "pedagang mimpi" atau mereka lebih memilih untuk "membangun bisnis baru daripada memperluas dan mempertahankan bisnis yang ada". Demikian juga Marchand \& Hermens (2015) mendefinisikan studentpreneur dan mengidentifikasi wirausahawan siswa sebaga fenomena yang muncul dan kemudian menunjukkan bahwa niat siswa untuk menjadi pengusaha telah dipelajari, namun bagaimana praktik kewiraswastaan tidak dipelajari. Tentunya ini bisa memberi kesempatan bagus, salah satunya adalah kita bisa mempelajari contoh kasus dengan contoh kasus yang luar biasa seperti kisah sukses Michael Dell, Bill Gate atau Mark Zuckerberg dan kondisi luar biasa, seperti pengaruh lingkungan pendidikan dan biaya saat memulai. bisnis rendah, dan sebagainya.

Ogunyemi (2011) menjelaskan bahwa studentpreneura adalah mereka yang pada siang hari mungkin terlihat seperti siswa biasa tapi di malam hari, mereka mengubah dunia. Mereka seperti orang kaya atau penting. Mereka adalah generasi baru manusia super. Mereka memegang rahasia kesuksesan dan pelengkap sejati. Masingmasing memiliki kekuatan untuk bermimpi ke depan, dan membuat visi mereka menjadi kenyataan. Mereka memiliki tingkat ketekunan dan tekad yang bahkan tidak bisa dipahami manusia. Beberapa menggambarkan mereka sebagai tokoh cerdas, bintang muda dalam bisnis, pemimpin masa depan, atau inovator generasi baru.

Torenberg (2012) menyatakan bahwa seorang wirausahawan mahasiswa tidak hanya tertarik untuk membangun bisnis, tapi dia juga jurusan sains politik yang memulai sebuah organisasi politik, menggunakannya sebagai platform untuk menghubungkan pemikiran dari disiplin ilmu lainnya. Bahkan, dia juga bisa menjadi siswa yang menggunakan "ruang kelas dan laboratorium sebagai platform, sumber daya, dan subsidi untuk membangun produk, proses atau layanan yang dapat dipasarkan" (Mars, Slaughter, \& Rhoades, 2008). Terkadang, wirausaha juga didefinisikan sebagai "wirausahawan akademis" namun sebagian besar penelitian tentang kewiraswastaan di bidang akademik berfokus pada anggota fakultas yang memiliki aktivitas kewirausahaan, bukan pada siswa (Bercovitz \& Feldman, 2008). Meskipun telah ada penelitian yang signifikan mengenai kewiraswastaan akademis, akademisi menjadi wirausahawan adalah fenomena yang agak marjinal bila dibandingkan dengan "banyaknya pengusaha mahasiswa yang berpendidikan dan dipelihara dalam konteks universitas, dan yang sering terus mengembangkan perusahaan baru mereka dalam interaksi. dengan universitas setelah lulus "(Politis, Winborg, \& Dahlstrand, 2012); (Marchand \& Hermens, 2015).

Menurut Naffziger, Hornsby \& Kuratko (1994), Manik \& Sidharta (2016) pengukuran kewiraswastaan yang banyak digunakan ditentukan oleh tiga faktor, yaitu; ciri kepribadian, ciri pribadi dan kontekstual dimana ketiga faktor tersebut adalah faktor internal. Peran universitas dapat mendorong 
keterkaitan dengan penciptaan pengusaha dengan mentransfer pengetahuan dan keterampilan yang sesuai (Sidharta \& Lusyana, 2014) untuk meningkatkan harga diri (Baum 1994) dan dapat menciptakan keefektifan bagi pengusaha pemula dalam memulai bisnis pertama (Gorman, Hanlon, \& King, 1997). Peningkatan kewiraswastaan dapat dilakukan oleh universitas melalui proses nilai pendidikan dan sikap, tujuan pribadi, kreativitas, pengambilan risiko dan pengendalian (Gibb, 1994) dan kualitas perbaikan diri memainkan peran penting dalam membentuk niat kewirausahaan pada siswa ( Shinnar, Hsu, \& Powell, 2014).

\section{Key Success Factor}

Key Success Factor pada umumnya, berkaitan dengan pencapaian tujuan dan sasaran di bidang manajemen, meski tidak selalu dinyatakan secara eksplisit. Kesuksesan dan kegagalan bisa diartikan sebagai ukuran manajemen yang baik atau acuh tak acuh. Dalam studi bisnis, konsep kesuksesan sering digunakan untuk mengacu pada kinerja keuangan suatu perusahaan. Namun, tidak ada definisi sukses yang diterima secara universal, dan kesuksesan bisnis telah ditafsirkan dalam banyak hal (Foley \& H, 1989); (Philip, 2011). Paling tidak ada dua dimensi kesuksesan yang penting, yaitu kesuksesan finansial versus lainnya dan kesuksesan jangka pendek dan jangka panjang. Dengan demikian, kesuksesan bisa memiliki bentuk yang berbeda, seperti survival, profit atau return on investment, pertumbuhan penjualan, jumlah karyawan, kebahagiaan, reputasi, dan sebagainya. Dengan kata lain, kesuksesan bisa dilihat memiliki arti berbeda oleh orang yang berbeda. Terlepas dari perbedaan ini, orang umumnya memiliki gagasan yang lebih penting, yaitu jenis usaha apa yang bekerja.

Faktor keberhasilan utama adalah keterampilan atau sumber daya yang dapat diinvestasikan oleh bisnis, yang menjelaskan sebagian besar perbedaan yang dapat diamati dalam nilai yang dirasakan dari tawaran dan / atau biaya relatif untuk mengajukan penawaran ke pasar (Bisp,
Sorensen, \& Grunert, 2001 , p 55); (Hung, Effendi, Talib, \& Rani, 2011). Menurut (Ghosh, Liang, Meng, \& Chan, 2001), faktor kunci keberhasilan didefinisikan sebagai faktor yang sangat penting untuk kinerja perusahaan yang superior daripada bertahan hidup. Hashim (2000) menggambarkan kesuksesan sebagai keefektifan perusahaan dalam mencapai tujuannya. Faktor keberhasilan yang diidentifikasi memenuhi kebutuhan pelanggan, hubungan kerja yang erat antara manajemen puncak dan karyawan, regionalisasi, kepemimpinan, ketersediaan sumber daya keuangan dan teknologi, dan dukungan. Penelitian berbasis survei terbaru berikut ini telah membahas faktor- faktor yang mempengaruhi keberhasilan UKM. (Indarti \& Langenberg, 2005) mengidentifikasi faktor kunci dalam menganalisis keberhasilan bisnis UKM yang mencakup karakteristik pengusaha, karakteristik UKM, dan elemen kontekstual pengembangan UKM.

\begin{tabular}{lcc}
\multicolumn{1}{c}{ Berdasarkan } & temuan & penelitian \\
sebelumnya, & faktor-faktor & yang \\
mempengaruhi & keberhasilan & UKM
\end{tabular}
dikategorikan sebagai berikut: 1 . Karakteristik pengusaha (Kristiansen, Furuholt, \& Wahid, 2003); dan (Rutherford \& Oswald, 2000) 2. Karakteristik UKM (Kristiansen, Furuholt, \& Wahid, 2003) 3. Manajemen dan mengetahui kinerjanya (Swierczek \& Ha, 2003) 4. Produk layanan (Wiklund,1998); dan (Hitt \& Ireland, 2000) 5. Pelanggan dan pasar (William, James, \& Susan, 2005) 6. Bagaimana melakukan bisnis dan kerjasama (Hitt \& Ireland, 2000); dan (Jarillo, 1988) 7. Sumber daya dan keuangan (Swierczek \& Ha, 2003); dan (Kristiansen, Furuholt, \& Wahid, 2003) 8. Strategi (McMahon, 2001) 9. Lingkungan eksternal (Huggins, 2000); dan (Indarti \& Langenberg, 2005) 10. Internet (Hesselmann \& Comcare, 2002) Selain itu, Gaskill \& Hyland (1989) juga mengidentifikasi enam keberhasilan bisnis utama, termasuk: kekuatan sumber daya, rencana bisnis, studi persaingan, pengukuran kinerja, dan kepuasan diri. Beberapa penelitian menemukan bahwa pengusaha pendiri harus digantikan oleh manajer profesional, yang mampu mengelola pertumbuhan organisasi dengan lebih baik 
(Chandler \& Jansen, 1992).

Sebaliknya, Willard, Krueger, \& Feeser (1992) menemukan bahwa pengusaha pendiri dapat memiliki kompetensi untuk bekerja dengan baik dengan manajer profesional. Pengusaha yang memiliki kompetensi yang diperlukan terutama di bidang operasi, keuangan, pemasaran, sumber daya manusia dan keterampilan manajemen adalah semua yang dibutuhkan agar bisnis lebih berhasil saat start up (Rose, Kumar, \& Yen, 2006). Selanjutnya, (Hashim, Mahasiswa, \& Ahamd, 2003) menemukan bahwa kepemimpinan yang kuat dan mendukung, komitmen karyawan, keterlibatan karyawan, dorongan gagasan baru, toleransi risiko, ambiguitas, konflik, komunikasi terbuka antar karyawan, pembagian keuntungan, orientasi pasar dan pelanggan, dan penekanan pada perilaku wirausaha adalah komponen kunci keberhasilan fakta atau kunci sukses penting. Untuk kesuksesan organisasi, Ayadurai \& Ahmad (2006) in Hung, Effendi, Talib, \& Rani (2011) percaya bahwa wirausahawan harus memiliki karakteristik yang: inovatif, kreatif, berpandangan jauh ke depan, berperilaku baik dalam urusan bisnis, atau tabah terhadap pendirian, memiliki pengetahuan dalam bisnis, berpikiran bisnis, mampu bekerja berjam-jam, memiliki jaringan yang baik dan memiliki jumlah kontak, mandiri, dan tangguh. Rose, Kumar, \& Yen (2006) mengemukakan faktor keberhasilan sebagai inisiatif pribadi, mempromosikan produk dan layanan, memahami kebutuhan pasar, dan memeriksa umpan balik pelanggan. Selain itu, inovasi juga terbukti menjadi salah satu elemen kunci keberhasilan (Sinha, 2003) dan ada hubungan yang signifikan antara kemampuan dan inovasi yang merupakan ciri khas kinerja UKM (Man \& Wafa, 2007).

Dalam penelitian ini, faktor kunci keberhasilan atau kunci keberhasilan yang akan digunakan sebagai indikator penelitian mengacu pada penelitian sebelumnya yang dilakukan oleh Lin (1998); Sen dan Taylor (2007); dan Mahrouq (2010) Namun, faktor utama yang diuji untuk mengukur peran yang ada dalam keberhasilan UKM adalah sebagai berikut: Struktur Perusahaan; Prosedur Teknis dan Teknologi yang digunakan oleh Perusahaan; Sumber Daya Manusia di Perusahaan; Struktur Keuangan Perusahaan; Pemasaran dan Produktivitas.

\section{Structure of the Firm}

Struktur perusahaan mencerminkan manajemen perusahaan yang efisien. Variabel yang paling penting dari faktor ini adalah mengelola perusahaan pada tahap awal melalui studi kelayakan yang jelas, dan efisiensi operasi manajerial di perusahaan dan struktur organisasi perusahaan. Indikator: patung-patung hukum dan kepemilikan perusahaan, sistem manajerial diikuti dalam perusahaan, studi kelayakan untuk tahap awal, bagan organisasi yang jelas, metode kontak yang jelas antara berbagai tingkat, sentralisasi kerja, karier yang jelas dan jalur manajerial (Mahrouq, 2010)

\section{Technical Procedures and Technology Used by the Firm}

Faktor ini dikaitkan dengan lima variabel: teknologi tinggi peralatan, penggunaan perencanaan dan rekayasa operasi produksi, sistem penelitian dan pengembangan, metode operasi dan teknologi baru dan otomatisasi. (Mahrouq, 2010)

\section{Human Resources at the Firm}

Employees know how; Skilled workers at the firm; Low level of employees turn over; Continuous training and capacity building for the employees; Financial and non-financial incentives for the employees

; Managerial development; Employees satisfaction; Higher management training and development; Employees safety net; Employees behavior and commitment. (Mahrouq, 2010)

\section{Financial Structure of the Firm}

Karyawan tahu caranya; Pekerja terampil di perusahaan; Tingkat rendah dari pergantian karyawan; Pelatihan berkelanjutan dan pengembangan kapasitas untuk karyawan; Insentif finansial dan non-finansial untuk karyawan; Pengembangan manajerial; 
Kepuasan karyawan; Pelatihan dan pengembangan manajemen yang lebih tinggi; Jaring pengaman karyawan; Perilaku dan komitmen karyawan. (Mahrouq, 2010)

\section{Marketing and Productivity}

Availability of raw materials at a local Ketersediaan bahan baku di tingkat lokal; Aktivitas oleh perusahaan; Permintaan akan produk dan layanan perusahaan; Kebijakan pemasaran diikuti oleh perusahaan; Segmen pasar khusus untuk produk perusahaan; Studi pasar pada tahap awal; Lokasi perusahaan; Menyajikan atau menyediakan produk atau layanan; Fasilitas pembayaran untuk klien Anda; Tindak lanjuti perkembangan pasar dan perubahan pasar; Promosi dan iklan untuk produk; Kebijakan harga; Kualitas produk; Pelanggan yang terus menerus perlu belajar; Layanan purna jual; Pengembangan dan penyesuaian produk sesuai kebutuhan; Jaringan perusahaan dengan perusahaan lain. (Mahrouq, 2010)

\section{METODE PENELITIAN}

Penelitian ini menggunakan metode deskriptif. Sampel dalam penelitian ini adalah siswa yang telah mengikuti kursus kewirausahaan dan bergabung dengan Indonesia Young Entrepreneurship Association di kampus. Mereka berasal dari UPI, UNPAD dan ITB. Sampel mencakup 300 responden. Teknik pengambilan sampel menggunakan simple random sampling. Teknik pengumpulan data menggunakan kuesioner, wawancara, dan observasi.

\section{HASIL DAN PEMBAHASAN}

Bagian ini menunjukkan data demografi dan karakteristik utama untuk responden. Berdasarkan data, mahasiswa wirausaha di tiga universitas negeri di Bandung, mayoritas sudah mengejar bisnis mereka antara 2-4 tahun dan didominasi oleh pria. Karakteristik reponden berikutny adalah berdasarkan faktor kunci kesuksesan.

Berdasarkan data pada Tabel 2, kita dapat menyimpulkan bahwa tidak ada perbedaan yang signifikan pada faktor- faktor kunci keberhasilan wirausaha siswa di UPI, UNPAD dan ITB.Prosedur teknis dan teknologi adalah kunci keberhasilan karena faktor ini terutama menyangkut penggunaan teknologi yang terkait dengan penggunaan internet. Teknologi telah menjadi hal yang sangat penting di balik kesuksesan wirausahawan dalam mengelola bisnisnya. Salah satu keunggulan pemanfaatan teknologi ini adalah mempengaruhi harga tetapi dapat membuat produk lebih menarik bagi konsumen.

Tabel 2 Rank of Success Factors

\begin{tabular}{|c|c|c|c|c|}
\hline No & $\begin{array}{c}\text { Key Success } \\
\text { Factor }\end{array}$ & UPI & UNPAD & ITB \\
\hline 1 & $\begin{array}{l}\text { Structure of } \\
\text { the firm }\end{array}$ & 3.8 & 3.8 & 3.9 \\
\hline 2 & $\begin{array}{l}\text { Technical } \\
\text { Procedures } \\
\text { and } \\
\text { Technology }\end{array}$ & 4.2 & 4.1 & 4.3 \\
\hline 3 & $\begin{array}{l}\text { Human } \\
\text { resources at } \\
\text { the firm }\end{array}$ & 2.7 & 2.9 & 2.9 \\
\hline 4 & $\begin{array}{l}\text { Financial } \\
\text { structure of } \\
\text { the firm }\end{array}$ & 3.1 & 3.6 & 3.8 \\
\hline 5 & $\begin{array}{l}\text { Marketing } \\
\text { and } \\
\text { Productivity }\end{array}$ & 3.2 & 3.4 & 3.6 \\
\hline
\end{tabular}

Struktur perusahaan memegang kunci kedua dalam menentukan keberhasilan suatu perusahaan. Hal ini disebabkan manajemen perusahaan yang efisien baik dalam studi kelayakan maupun efisiensi manajemen operasional dan struktur organisasi yang memadai sangat mendukung keberhasilan bisnis, Sektor keuangan menjadi faktor kunci keberhasilan ketiga dalam penelitian ini. Pengelolaan sumber keuangan dan pendanaan merupakan faktor yang sangat penting dalam pengembangan bisnis. Salah satu faktor penghambat kemajuan bisnis adalah keterbatasan sumber pendanaan. Selama ini pendanaan kegiatan kemahasiswaan untuk mahasiswa di antaranya berasal dari Dikti melalui Student Entrepreneurial Program (PMW) yang diberikan kepada para pebisnis mahasiswa di universitas.

Pemasaran dan produktivitas menempati faktor keberhasilan keempat 
untuk wirausaha siswa dalam mengelola bisnisnya. Jangkauan bisnis sebenarnya masih banyak yang lokal, tetapi dengan bantuan pemasaran melalui media sosial maka sudah banyak yang memasarkannya ke tingkat nasional. Sementara untuk bahan baku masih menggunakan banyak bahan lokal. Dalam hal produk, sebenarnya produk yang dijual tidak melakukan banyak inovasi yang spektakuler, masih barang biasa dan perlu meningkatkan reproduksi mereka.

Faktor terakhir yang menjadi kunci keberhasilan bagi pebisnis adalah manajemen sumber daya manusia untuk perusahaan. Dalam pengelolaan sumber daya manusia masih terdapat tingkat turnover karyawanBi yang tinggi. Salah satu faktor yang perlu diperiksa di sini adalah manajemen sumber daya manusia yang tidak memadai dalam hal pergantian, perilaku dan komitmen.

\section{KESIMPULAN DAN SARAN}

Agar berhasil dalam bisnis, pelajar harus mempertimbangkan, prosedur teknis dan teknologi, struktur perusahaan, sumber daya manusia di perusahaan, struktur keuangan perusahaan, pemasaran dan produktivitas. Tidak ada perbedaan signifikan pada faktor-faktor kunci keberhasilan studentpreneur di tiga universitas. Pengembangan sumber daya manusia harus ditingkatkan dalam hal pergantian, perilaku, dan komitmen.

\section{DAFTAR PUSTAKA}

Ayadurai, S., \& Ahmad, W. (2006). A study on the critical success factors of women entrepreneurs in small and medium enterprises (SMEs) in Malaysia. Paper presented at the International Council for Small Business (ICSB) 51st World Conference, Melbourne.

B. (2001). The key success factors, distinctive capabilities and strategic thrust of top SMEs in Singapore. Journal Business Research, 51, 209221.

Baghai, M., Coley, S., \& White, D. (2000). The Alchemy of Growth,. New York,
NY: Basic Books.

Baum, R. (1994). The Relation of Trait, Competencies, Vision, Motivation, and Strategy to Venture Growth. Unpublished Doctoral Dissertation, University of Maryland.

Bercovitz, J., \& Feldman, M. (2008). 'Academic Entrepreneurs:

Organizational Change at the Individual'. Organization Science, vol. 19, no. 1, pp. 69-89.

Bisp, S., Sorensen, E., \& Grunert, K. (2001). Using the key success factor concept in competitor intelligence and benchmarking. Competitive Intelligence Review, 9(3), 55-67.

Chandler, G., \& Jansen, E. (1992). The founder's self-assessed competence and venture performance. J. Business Venturing, pp: 223-236.

Chen, Y., \& Lai, M. (2010). Factors influencing the entrepreneurial attitude of Taiwanese tertiary-level business students. Social Behavior and Personality: an international journal, 38(1), 1-12.

Foley, P., \& H, G. (1989). Small business success. London: Chapman.

Gaffar, Vanessa and Heny Hendrayati. (2016). Peningkatan Spirit Kewirausahaan Melalui Pendidikan Kewirausahaan sebagai suatu Lifelong Learning Process. Laporan Akhir Hibah Strategi Naisonal.

Gaskill, G., \& Hyland, J. (1989). Starting and managing a small business. Strategic Finance, 71(6), 28.

Ghosh, B., Liang, T., Meng, T., \& Chan,

Gibb, A. (1994). Do we really teach (Approach) small business the way we should? Journal of Small Business and Entrepreneurship, 11(2), 4-27.

Gorman, G., Hanlon, D., \& King, W. (1997). Some research perspectives on entrepreneurship education, enterprise education and education for small business management: A ten-year literature review. International Small Business Journal, 15(3), 56-77.

Hashim, M. (2000). A proposed strategic 
Framework for SMEs success. Malaysian Management Review, 35(2), 32-43.

Hashim, M., Mahajar, A., \& Ahamd, S. (2003). Innovative practices of Malaysian Firms: Some evidence from Enterprise 50 Winners. Malaysian Management Review, 38 (2), 19-27.

Hesselmann, H., \& Comcare, P. (2002). Benchmarking national and regional e-business policies for SMEs. Final report of the "E- business Policy Group.

Hitt, M., \& Ireland, R. (2000). The intersection of entrepreneurship and strategic management research. Handbook of entrepreneurship, 4563.

Huggins, R. (2000). The success and failure of policy-implanted inter- firm network initiatives: motivations, processes and structure. Entrepreneurship and Regional Development, 12(2), p.211-236.

Hung, D., Effendi, A., Talib, L., \& Rani,

N. (2011). A preliminary study of top SMEs in Malaysia: Key success factor vs Government support program. Journal of Global Business and Economics, 2(1), 48- 58.

Indarti, N., \& Langenberg, M. (2005). A study of factors affecting business success among SMEs: Empirical evidences from Indonesia. Asian Social Science, 7(5), 67-86.

Jarillo, J. (1988). On strategic networks. Strategic Management Journal, 9(1), p.31-41.

Kourilsky, M., \& Walstad, W. (1998). Entrepreneurship and female youth: Knowledge, attitude, gender differences, and educational practices. Journal of Business Venturing, 13(1), 77-88.

Kristiansen, S., Furuholt, B., \& Wahid, F. (2003). Internet cafe entrepreneurs: pioneers in information dissemination in Indonesia. The International Journal of Entrepreneurship and Innovation,
4(4), p.251-263.

Lin, C., (1998). Success Factors of Small and Medium-Sized Enterprises in Taiwan: An Analysis of Cases, Journal of Small Business Management, 36 (4).

Man, M., \& Wafa, S. (2007). The relationship between distinctive capabilities and the performance of small and mediumsize enterprises (SMEs) in Malaysia. In Proceedings of the 13th Asia Pacific Management Conference, Melbourne, Australia, 11-19.

Manik, E., \& Sidharta, I. (2016). Entrepreneurial Intention on Studentpreneurs to become Entrepreneur. International Review of Management and Marketing, 6, 3.

Marchand, J., \& Hermens, A. (2015). Student entrepreneurship: A research agenda. International Journal of Organizational Innovation (Online), 8(2), 266.

Mahrouq, Maher AL (2010) Success Factors Of Small And Medium- Sized Enterprises (Smes): The Case Of Jordan. Anadolu University Journal Of Social Sciences Cilt/Vol.: 10Sayı/No: $1: 1-16$ (2010

Mars, M., Slaughter, S., \& Rhoades, G. (2008). 'The State-Sponsored Student Entrepreneur'. The Journal of Higher Education, vol. 79, no. 6, pp. 638-70.

McMahon, R. (2001). Growth and performance of manufacturing SMEs: The influence of financial management characteristics. International Small Business Journal, 19(3), p.10-28.

Naffziger, D., Hornsby, J., \& Kuratko, D. (1994). A proposed research model of entrepreneurial motivation. Entrepreneurship Theory and Practice, 18(3), 29-43.

Nora, A., Cabrera, A., Hagedorn, L., \& Pascarella, E. (1996). Differential impacts of academic and social experiences on college-related behavioral outcomes across different ethnic and gender groups at four-year institutions gender groups at fouryear institutions. Research in Higher 
Educati. Research in Higher Education, 37(4), 427-451.

Ogunyemi, J. (2011). How to be a Student Entrepreneur. Ecademy Press.

Pascarella, E., \& Terenzini, P. (2005). How college affects students (Vol. 2): A third decade of research. San Francisco: Jossey-Bass/Wiley.

Perna, L. (2006). Studying college choice: A proposed conceptual model. In

J.C. Smart (Ed.), Higher education: Handbook of theory and research. New York: Springer Publishing.

Philip, M. (2011). Factors affecting business success of small \& medium enterprises (SMEs). Amity Global Business Review, 6(1), 118136.

Politis, D., Winborg, J., \& Dahlstrand, A. (2012). Exploring the resource logic of student entrepreneurs. International Small Business Journal, 30(6), pp. 659-683.

Rose, R., Kumar, N., \& Yen, L. (2006). Entrepreneurs success factors and escalation of small and mediumsized enterprises in Malaysia. Journal of Social Sciences, 2(3), 74-80.

Rose, R., Kumar, N., \& Yen, L. (2006). Entrepreneurs success factors and escalation of small and mediumsized enterprises in Malaysia. Journal of Social Sciences, 2(3), 74-80.

Rutherford, M., \& Oswald, S. (2000). Antecedents of small business performance. New England Journal of Entrepreneurship, 3(2), 21.

Sen, B. and Taylor, R., (2007). Determining the Information Needs of Small and Medium-Sized Enterprises: A Critical Success Factors Analysis, Information Research, 12 (4).

Shay, J., \& Terjensen, S. (2005). Entrepreneurial aspirations and intentions of business students: A gendered perspective. Paper presented at the Babson Entrepreneurship Conference, Boston, MA.

Shinnar, R., Hsu, D., \& Powell, B. (2014). Self-efficacy, entrepreneurial intentions, and gender: Assessing the impact of entrepreneurship education longitudinally. The International Journal of Management Education, 12, 561-570.

Sidharta, I., \& Lusyana, D. (2014). Analisis faktor penentu kompetensi berdasarkan konsep knowledge, skill, dan ability (KSA) Di Sentra Kaos Suci Bandung. Jurnal Computech \& Bisnis, 8(1), 49-60.

Sinha, A. (2003). Experience of SMEs in south and south-east Asia. South Asia Enterprise Development Facility, 118.

St. John, E. (2003). Refinancing the college dream: Access, equal opportunity, and justice for taxpayers. Baltimore, MD: The Johns Hopkins University Press.college-related behavioral outcomes across different ethnic and gender groups at four-year institutions. Research in Higher Education, 37(4), 427-451.

Swierczek, F., \& Ha, T. (2003). Entrepreneurial orientation, uncertainty avoidance and firm performance: an analysis of Thai and Vietnamese SMEs.

International Journal of Entrepreneurship and Innovation, 4(1), p.46-58.

Tinto, V. (1993). Leaving college: Rethinking the causes and cures of student attrition (2nd ed.). Chicago: The University of Chicago Press.esearch in Higher Education, 37(4), 427-451.

Torenberg, E. (2012). Find Your Inner Entrepreneur. The Michigan Daily.

Wang, C., \& Wong, P. (2004). Entrepreneurial interest of university students in Singapore. Technovation, 24(2), 163-172.

Wiklund, J. (1998). Small Firm Growth and Performance Entrepreneurship and Beyond. Internationella Handelshögskolan.

Willard, G., Krueger, D., \& Feeser, H. (1992). In order to grow, must the founder go: A comparison of 
Journal IMAGE | Volume 8, Number 2, November 2019, page 77-86

performance between founder and non-founder managed high-growth

manufacturing firms. Journal of Business Venturing, 7(3),, 181-194. 
Journal IMAGE | Volume 8, Number 2, November 2019, page 77-86 